\title{
Core-binding factor beta is required for osteoblast differentiation during fibula fracture healing
}

\author{
Tuanmao Guo ${ }^{1}$, Yanli Xing ${ }^{2}$, Zhongning Chen ${ }^{1}$, Xianhong Wang ${ }^{1}$, Haiyun Zhu' ${ }^{1}$ Lan Yang ${ }^{1}$ and Yong Yan $^{3}$
}

\begin{abstract}
Background: Growing evidence has implicated core-binding factor beta (Cbfb) as a contributor to osteoblast differentiation, which plays a key role in fracture healing. Herein, we aimed to assess whether Cbfb affects osteoblast differentiation after fibula fracture.

Methods: Initially, we established a Cbfb conditional knockout mouse model for subsequent studies. Immunohistochemical staining was conducted to detect the expression of proliferating cell nuclear antigen (PCNA) and collagen II in the fracture end. Next, we isolated and cultured osteoblasts from specific Cbfb conditional knockout mice for BrdU analysis, alkaline phosphatase (ALP) staining, and von Kossa staining to detect osteoblast viability, differentiation, and mineralization, respectively. Western blot analysis and reverse transcription-quantitative polymerase chain reaction (RT-qPCR) were used to detect the expression of osteoblast differentiation-related genes.

Results: The Cbfb conditional knockout mice exhibited downregulated expression of PCNA and collagen II, reduced ALP activity, and mineralization, as well as diminished expression of osteoblast differentiation-related genes. Further, Cbfb knockout exerted no obvious effects on osteoblast proliferation.

Conclusions: Overall, these results substantiated that Cbfb could promote fibula fracture healing and osteoblast differentiation and thus provided a promising therapeutic target for clinical treatment of fibula fracture.
\end{abstract}

Keywords: Core-binding factor beta, Fracture healing, Osteoblast, Differentiation, Knockout

\section{Background}

Fibula fracture is a relatively common long bone fracture, which often leads to soft tissue complications and non-union [1]. As such, fibula fracture represents a recurring injury that often needs stabilization through orthopedic surgery approaches [2]. Fracture healing is a complicated biological process since it entails specific regenerative patterns and involves altered expression of several thousand genes [3]. The procedure of preemptive anatomical reduction and fixation can facilitate the

\footnotetext{
*Correspondence: 15389460555@163.com

${ }^{2}$ The Pharmacy Department, Xianyang Central Hospital, Xianyang 712000, People's Republic of China

Full list of author information is available at the end of the article
}

healing of fibula fracture and restoration of lowerextremity alignment [4]. Fractures that cannot be made to heal or unite quickly and completely are responsible for pain and loss of mobility [5]. Osteoblasts, which originate from mesodermal progenitors, are essential for bone-forming and mineralization processes [6]. Osteoblasts express receptors for several hormones including estrogen, parathormone (PTH), and glucocorticoids, all of which participate in the regulation of osteoblast differentiation [7], and are necessary for normal fracture healing [8].

Core-binding factor beta (Cbfb), also known as polyomavirus enhancer binding protein 2 beta gene and SL3 enhancer factor 1 , can fuse to form a chimeric protein 
[9]. Cbfb is essential for embryonic bone morphogenesis and postnatal cartilage and bone formation, through its control of the balance of chondrocyte differentiation and proliferation via regulation of Indian hedgehog expression and parathyroid hormone-related protein receptor [10]. Cbfb knockout mice present with severely delayed bone formation, which is characterized by diminished osteoblast differentiation and maturation and impaired skeletal development [10]. Similar findings revealed by Fukuda et al. showed that Cbfb favored osteoblast differentiation and bone formation [11]. However, the role of $\mathrm{Cbfb}$ in fracture healing remains to be substantiated, whereas other targets, such as $\mathrm{C} 1 \mathrm{q} / \mathrm{TNF}$-related protein 3 (CTRP3) and nuclear factor erythroid 2-related factor 2 (Nrf2), have been highlighted in fracture healing based on their involvement in endochondral ossification and osteoblast metabolism [12-14], indicating the great potential of $\mathrm{Cbfb}$ for fracture healing management. In addition, $\mathrm{Cbfb}$ has been reported to modulate bone development through stabilizing runt-related transcription factor (Runx) family proteins, and Runx 2 serves as a critical target in fracture healing [15-17]. Given the aforementioned evidence, we conducted this study to ascertain specific mechanistic actions of $\mathrm{Cbfb}$ in fibula fracture healing via regulation of osteoblast differentiation in an animal model.

\section{Materials and methods}

\section{Ethics statement}

All experimental procedures were in strict accordance with the requirements of the Animal Ethics Committee of Xianyang Central Hospital. Extensive efforts were made to ensure minimal suffering of the animals used during the study.

\section{Construction of $\mathrm{Cbfb}$ conditional knockout mouse model}

Loxp was inserted at both ends of the Cbfb allele to construct Cbfb fluorine and oxygen (Flox) mice (Jackson Lab, CA, USA), which were hybridized with Dermo promoter Cre (Cyclization Recombination Enzyme) mice (Jackson Lab, CA, USA), and the first filial generation $\mathrm{Cbfbf} / \mathrm{f}$; Dermo-Cre mice were obtained. These first filial generation mice were hybridized with $\mathrm{Cbfb}$ Flox mice, yielding the second generation of experimental group (Cbfbf/f; Dermo-Cre mice) with specific knockdown of $\mathrm{Cbfb}$ in mesenchymal stem cells. The littermate $\mathrm{Cbfbf} / \mathrm{f}$ and $\mathrm{Cbfb} / \mathrm{f}+$ mice were taken as the controls of wild type (WT) mice.

\section{Identification of Cbfb conditional knockout in mouse genotype}

Mice at postnatal age of 2-3 weeks were selected and the tips of their tails $(2-3 \mathrm{~mm})$ were collected and placed in 0.2 $\mathrm{mL}$ mouse tail digestive juice added with $4 \mu \mathrm{L}$ proteinase $\mathrm{K}$ solution (Yeasen Biotechnology Co., Ltd., Shanghai, China) and incubated overnight at $55^{\circ} \mathrm{C}$ with shaking. Next, the samples were added with $0.1 \mathrm{~mL} 6 \mathrm{M} \mathrm{NaOH}$ solution (Guangzhou Laiyu Chemical Co., Ltd, Guangzhou, China), shaken violently and centrifuged. The supernatant was added to $0.5 \mathrm{~mL}$ of $95 \%$ ethanol (Sinopharm Chemical Reagent Co., Ltd., Beijing China), shaken up and down 35 times, and allowed to stand at room temperature for 10 $\mathrm{min}$, followed by centrifugation for $5 \mathrm{~min}$. Then, the precipitate was washed with $1 \mathrm{~mL}$ of $75 \%$ ethanol for $15 \mathrm{~s}$ and dried, whereupon $0.1 \mathrm{~mL} 0.1$ TE solution $(\mathrm{pH}=8.0$; Shanghai Haling Biotechnology Co., Ltd., Shanghai, China) was added and shaken for $1 \mathrm{~h}$ at $220 \mathrm{rpm}$ and $65^{\circ} \mathrm{C}$ to dissolve the DNA. The forward sequence of $\mathrm{Cbfb}$ identification primers was $5^{\prime}$-TGTCTGAAGACAACTACAGTGT AC-3', and the reverse sequence was $5^{\prime}$-CTCTCTGAAC ACTATATCAGTTCC-3'. The forward sequence of CRE (Cyclization Recombination Enzyme) identification primers was 5'-CCTGGAAAATGCTTCTGTCCGTTTGCC-3', and the reverse sequence was $5^{\prime}$-GAGTTGATAGCTGG CTGGTGGCAGATG-3'. The reaction conditions of reverse transcription quantitative polymerase chain reaction (RT-qPCR) consisted of pre-denaturation at $94^{\circ} \mathrm{C}$ for 5 min, denaturation at $94^{\circ} \mathrm{C}$ for $45 \mathrm{~s}$, annealing at $54^{\circ} \mathrm{C}$ (CRE) and $57^{\circ} \mathrm{C}(\mathrm{Cbfb})$ for $45 \mathrm{~s}$, extension at $72^{\circ} \mathrm{C}$ for $45 \mathrm{~s}$, with a total of 30 cycles, and elongation at $72^{\circ} \mathrm{C}$ for $5 \mathrm{~min}$. The PCR was performed in a 2720 thermal cycler (Applied Biosystems, Thermo Fisher Scientific Inc., Waltham, MA, USA). The PCR products were separated using $1.0 \%$ agarose gel electrophoresis and photographed under an ultraviolet imaging system. The position of PCR product bands served to judge the size of the product fragments and then determine the genotypes of the mice.

\section{Establishment of fracture healing model}

A total of 30 7-week-old mice were divided into control and experimental groups $(n=15)$. The mice were fixed on a homemade autopsy table. An incision about 5-mm long was made along the proximal part of right lateral leg 12-mm away from the bone nodule. The soft tissues and muscles surrounding the fibula were separated by blunt dissection, and bleeding was staunched for exposure of the fibula, followed by transverse shearing. Mice with a deformity of the fracture or otherwise failing to meet the model requirements were excluded. Five mice for each group were subsequently euthanized at days 1 , 14 , and 28 after injury (Supplementary figure 1). Here, the fracture end and its surrounding tissues were collected for subsequent experiments.

\section{Streptavidin-perosidase (SP) assay}

The specimens rinsed using normal saline and then fixed in $4 \%$ paraformaldehyde ( $\mathrm{pH}=7.4$, Beijing Cellchip Biotechnology Co., Ltd., Beijing, China) at $4^{\circ} \mathrm{C}$ for $24-48 \mathrm{~h}$. 
Next, decalcification was conducted by incubation in $200 \mathrm{~g} / \mathrm{L}$ ethylenediamine tetraacetic acid (EDTA) (Baoding Kaiyue Chemical Co., Ltd., Hebei, China) for 4 weeks, with replacement of the decalcification fluid every 3 days. Next, the specimens were dehydrated with gradient ethanol, cleared with xylene (Changsha Tang Hua Chemical Trading Co., Ltd., Changsha, China) and vertically embedded in paraffin. The paraffin-embedded specimens were placed in a $4^{\circ} \mathrm{C}$ refrigerator and later sectioned and stained using Safranin-O/Fast Green for microscopic examination of the fracture healing site. Immunohistochemical staining was carried out to detect the expression of proliferating cell nuclear antigen (PCNA) and collagen II in the fracture end. The stained slices were observed under an optical microscope (XSP-36, Boshida Optical Instruments, Shenzhen, China) in five randomly selected fields of view per slice, with counting of 100 cells in each field of view to calculate the average proportion of positive cells. The experiment was conducted in triplicate. The primary antibody PCNA and collagen II was purchased from Abcam Inc. (Cambridge, MA, USA) and the secondary antibody was purchased from Shanghai MICROTEK Biotechnology Co., Ltd. (Shanghai, China).

\section{Cell culture and detection of cell proliferation and differentiation}

Osteoblast precursor cells were isolated and then inoculated into a cell culture dish at a density of $3 \times 10^{3}$ cells/ $\mathrm{cm}^{2}$. Upon reaching confluence, the cells were added with osteoblast induction medium: BGJB medium (Thermo Fisher Scientific Inc., Waltham, MA, USA) containing $10 \%$ fetal bovine serum (FBS), $50 \mu \mathrm{g} / \mathrm{mL} \mathrm{L}$-ascorbic acid (A4544, Sigma-Aldrich Chemical Company, St Louis, MO, USA) and $5 \mu \mathrm{g} \beta$-glycerolphosphate (G9891, Sigma-Aldrich Chemical Company, St Louis, MO, USA). Then, the 5-bromo-2'-deoxyuridine (BrdU) labeling method was used to measure osteoblast proliferation. Next, the cells were colored using 3,3'-diaminobenzidine (DAB) and observed under a microscope, with positive cells presenting with brownish yellow color. At the 14th day, alkaline phosphatase (ALP) staining (A2356, Sigma-Aldrich Chemical Company, St Louis, MO, USA) was adopted to detect cell differentiation. At the 21st day, von Kossa staining (Thermo Fisher Scientific Inc., Waltham, MA, USA) was applied to test the mineralization of osteoblasts.

\section{RNA isolation and quantitation}

Total RNA was extracted from primary osteoblasts using Trizol. Then, the reverse transcription was conducted using Invitrogen SuperScript VILO Master Mix kit (Thermo Fisher Scientific Inc., Waltham, MA, USA). Then, RT-qPCR was performed on a PCR instrument
(Applied Bio-systems, Foster City, CA, USA) using SYBR Green (Thermo Fisher Scientific Inc., Waltham, MA, USA). The primers used are shown in Supplementary Table 1.

\section{Western blot analysis}

The cells were rinsed twice with phosphate-buffered saline (PBS) and then added with loading buffer for heating at $95^{\circ} \mathrm{C}$ for $10 \mathrm{~min}$. The proteins were separated by $10 \%$ polyacrylamide gel electrophoresis (Boster Biological Technology Co., Ltd., Wuhan, Hubei, China) (40 $\mu \mathrm{g} /$ well) and then transferred onto polyvinylidene fluoride (PVDF) membranes using the wet transfer method. The membranes were blocked with $5 \%$ bovine serum albumin (BSA) at room temperature for $1 \mathrm{~h}$ and then incubated with primary antibodies diluted at 1: 500-1: 1000: Osteocalcin, (AM0911, Millipore, Billerica, MA, USA), Osterix, (ab22552, Abcam Inc., Cambridge, MA, USA) and ATF4 (abl05383, Abcam Inc., Cambridge, MA, USA) at $4^{\circ} \mathrm{C}$ overnight. After being rinsed three times (5 min/time) with Tris-buffered saline Tween-20 (TBST), the membranes were added with the corresponding secondary antibody (Abcam Inc., Cambridge, MA, USA) (Shanghai Precision \& Scientific Instrument Co., Ltd., Shanghai, China) and incubated at room temperature for $1 \mathrm{~h}$, followed by three washes with TBST (5 min/time). The immunocomplexes on the membrane were visualized using enhanced chemiluminescence (ECL) reagent (Shanghai Genmed Gene Pharmaceutical Technology Co., Ltd., Shanghai, China) and band intensities were quantified using a multifunctional imaging system.

\section{Statistical analysis}

Statistical analyses were conducted using SPSS 19.0 statistical software (IBM Corp. Armonk, NY, USA). Measurement data were expressed as mean \pm standard deviation and compared by unpaired $t$ test between two groups. A $p<0.05$ demonstrated statistical significance.

\section{Results}

\section{Identification of $\mathrm{Cbfb}$ conditional knockout mice}

After extracting the DNA of tails of mice following $\mathrm{Cbfb}$ conditional knockout, we used RT-qPCR to identify mouse genotypes, including WT, knocked out of fifth exon of $\mathrm{Cbfb}$, insertion of Loxp fragments at both ends of the $\mathrm{Cbfb}$ allele, and the sequence with $\mathrm{CRE}$ recombinase, as illustrated in Fig. 1.

\section{Histological observation of morphological characteristics of Cbfbf/f; Dermo-Cre mice}

At the 1st day after fracture, the staining results revealed that most fracture ends of $\mathrm{Cbfbf} / \mathrm{f}$; Dermo-Cre mice and WT mice were filled with fibrous tissues. At the 14th 


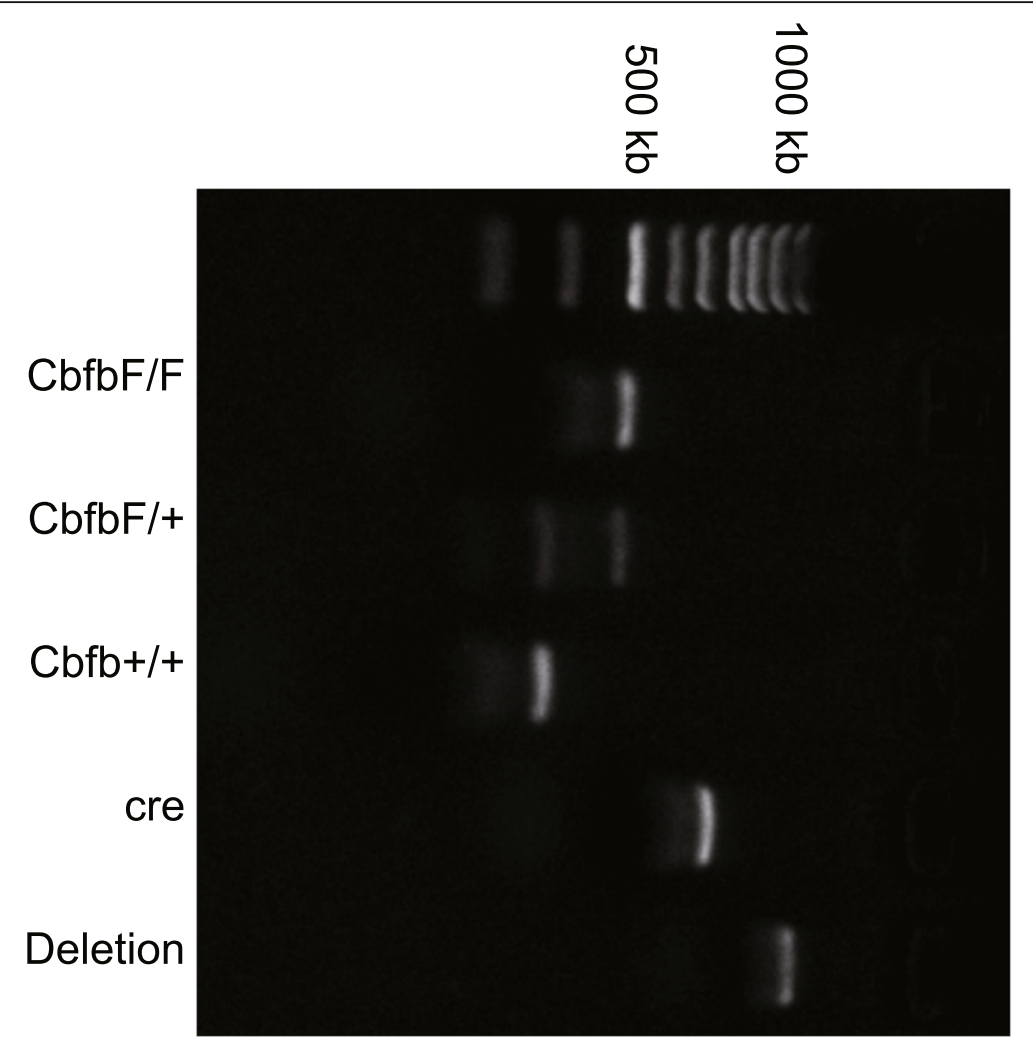

Fig. 1 Identification of Cbfb conditional knockout mice

day after fracture, chondrocytes at the fracture end of WT mice were significantly decreased in number and hypertrophic and part of the cartilage callus had turned into bony callus. However, the number of chondrocytes of $\mathrm{Cbfbf} / f$; Dermo-Cre mice had increased significantly and now formed a large proportion of the cartilage callus. At the 28th day after fracture, the fractures of WT mice were healed, accompanied by regularly distributed bone trabecula. However, the bone trabecula of Cbfbf/f; Dermo-Cre mice were observed to have a disordered arrangement, and the fracture healing was arrested at the shaping stage, with a paucity of chondrocytes (Fig. 2).

\section{Cbfb knockout decreases expression of PCNA and collagen II}

Immunohistochemical staining analysis of Collagen II (Fig. 3 left panel) revealed no obvious difference between the collagen II expression of the WT and the Cbfbf/f; Dermo-Cre mice on the 1st day after the fracture. On the 14th and 28th days, the fractured ends of the WT mice were mostly composed of chondrocytes, but only a few chondrocytes were observed in the Cbfbf/f; Dermo-Cre mice. At day 14 and 28, the collagen II expression was downregulated in the WT and Cbfbf/f; Dermo-Cre mice, whereas the latter presented more significant downregulation.
Meanwhile, immunohistochemical staining analysis of PCNA (Fig. 3 right panel) showed that on first days after fracture, the fracture end was mainly composed of undifferentiated fibroblasts and cartilage precursor cells. The positive expression of PCNA was observed to be diminished both in the WT and Cbfbf/f; Dermo-Cre groups. On the 14th and 28th days after fracture, the number of cells in the proliferative phase of fracture ends was decreased, and the PCNA positive expression was down-regulated in the WT mice and the Cbfbf/f; Dermo-Cre mice, whereas the latter exhibited much more distinct downregulation.

\section{Cbfb knockout inhibits ALP activity and mineralization}

The results obtained from ALP staining and von Kossa staining indicated that the activity of ALP in osteoblasts was decreased in the $\mathrm{Cbfbf} / \mathrm{f}$; Dermo-Cre group, and osteoblast differentiation was inhibited (Fig. 4a). The calcium nodules of osteoblasts in the $\mathrm{Cbfbf} / \mathrm{f}$; Dermo-Cre mice were much fewer/smaller than those in the WT mice, and the extent of mineralization was inhibited (Fig. 4b).

Cbfb knockout has no effects on osteoblast proliferation Subsequent BrdU results showing yellow-brown proliferating cells, with no statistically significant difference in 


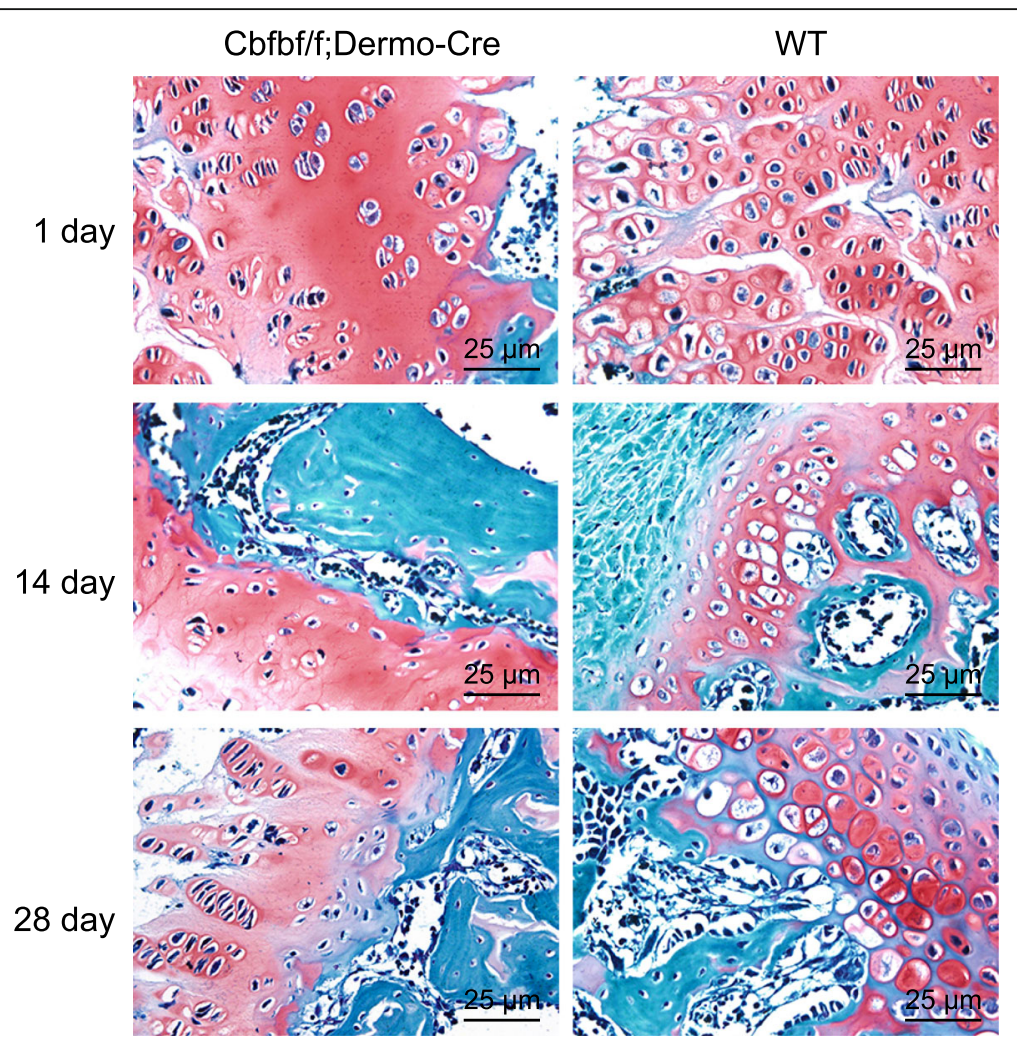

Fig. 2 Observation of morphological characteristics of Cbfbf/f; Dermo-Cre mice $(\times 400)$. Left panels, morphology of healed tissues of Cbfbf/f; Dermo-Cre mice at days 1, 14, and 28 following fracture. Right panels, morphology of healed tissues of WT mice at days 1, 14, and 28 following fracture

the proportion of positive cells between the $\mathrm{Cbfbf} / \mathrm{f}$; Dermo-Cre mice and the WT group $(p>0.05)$ (Fig. 5). This indicates that Cbfb knockout did not affect osteoblast proliferation.

\section{Cbfb knockout decreases osteoblast differentiation}

On the 14th day after the fracture, RT-qPCR assay revealed lower mRNA expression of the osteoblast differentiation-related genes, including ALP, Bglapl, Runx2, and SPPL, in the Cbfbf/f; Dermo-Cre mice than that in the WT mice $(p<0.05)$ (Fig. 6a). Western blot analysis showed varying degrees of reduced protein expression of the osteoblast differentiation-related genes Osteocalcin, Atf4, and Osterix in osteoblasts after Cbfb knockout, indicating inhibition of osteoblast differentiation. Compared with the WT mice, the mRNA and protein expression of osteocalcin, Atf4, and Osterix in the $\mathrm{Cbfb} / \mathrm{f}$; Dermo-Cre mice were reduced to different degrees (Fig. 6b).

\section{Discussion}

Fracture healing represents a unique biologic process that begins with an initial inflammatory response, during which bone and the immune system interact with each other closely [18]. CBF $\beta$ serves as a non-
DNA-binding partner of all Runx proteins and is essential for transcription activity of CBF transcription factors [19]. A growing number of studies have recognized the Cbfb gene to be a critical factor in bone morphogenesis, but the underlying molecular mechanisms remain largely unknown $[10,20,21]$. In this study, we confirmed that $\mathrm{Cbfb}$ expression was associated with fibula fracture healing and osteoblast differentiation. The main findings of our study indicated that $\mathrm{Cbfb}$ could potentially promote fibula fracture healing and osteoblast differentiation.

The shortened limbs and lower weight of $\mathrm{Cbfbf} / \mathrm{f}$; Dermo-Cre mice, indicated a delay in the fracture healing, accompanied by less formation of fracture callus. Fracture healing is considered to be a regenerative process consisting of many phases, each of which involves the formation of a variety of tissue types [22]. The formation of fracture callus appears during the secondary phase bone healing and imparts mechanical stability to the healing fracture [23]. A previous study has uncovered that mice constitutively lacking epithelial $\mathrm{Cbfb}$ exhibited short incisors, marked underdevelopment of the cervical loop, and diminished expression of epithelial Fgf9 expression and mesenchymal Fgf3 and Fgf10 in the cervical loop 

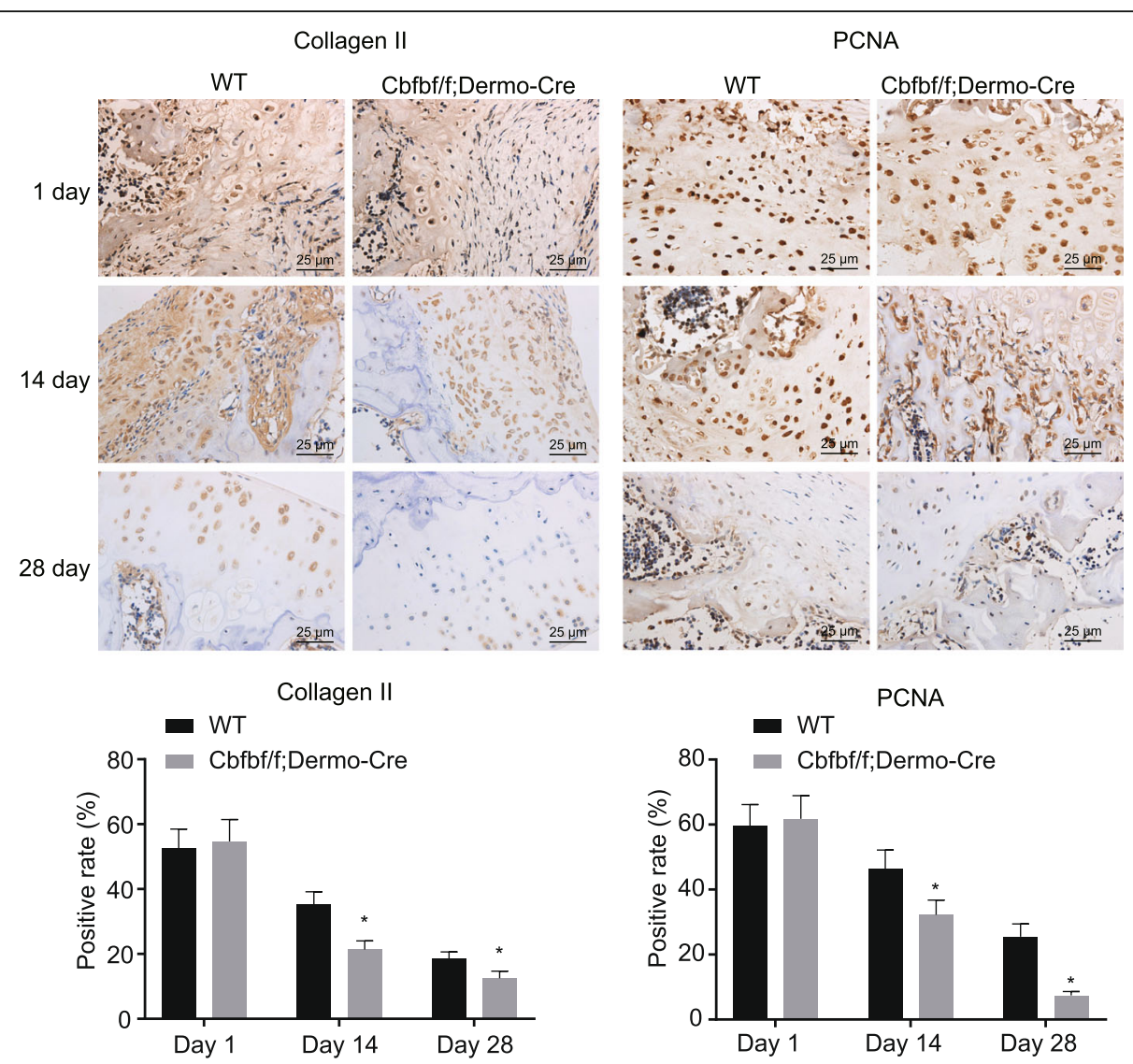

Fig. 3 Cbfb knockout decreases expression of collagen II ( $\times 400)$ and PCNA ( $\times 400)$. Measurement data were expressed as mean \pm standard deviation. Data comparison was conducted using independent samples $t$ test. ${ }^{*} p<0.05$ versus the WT group. $n=3$
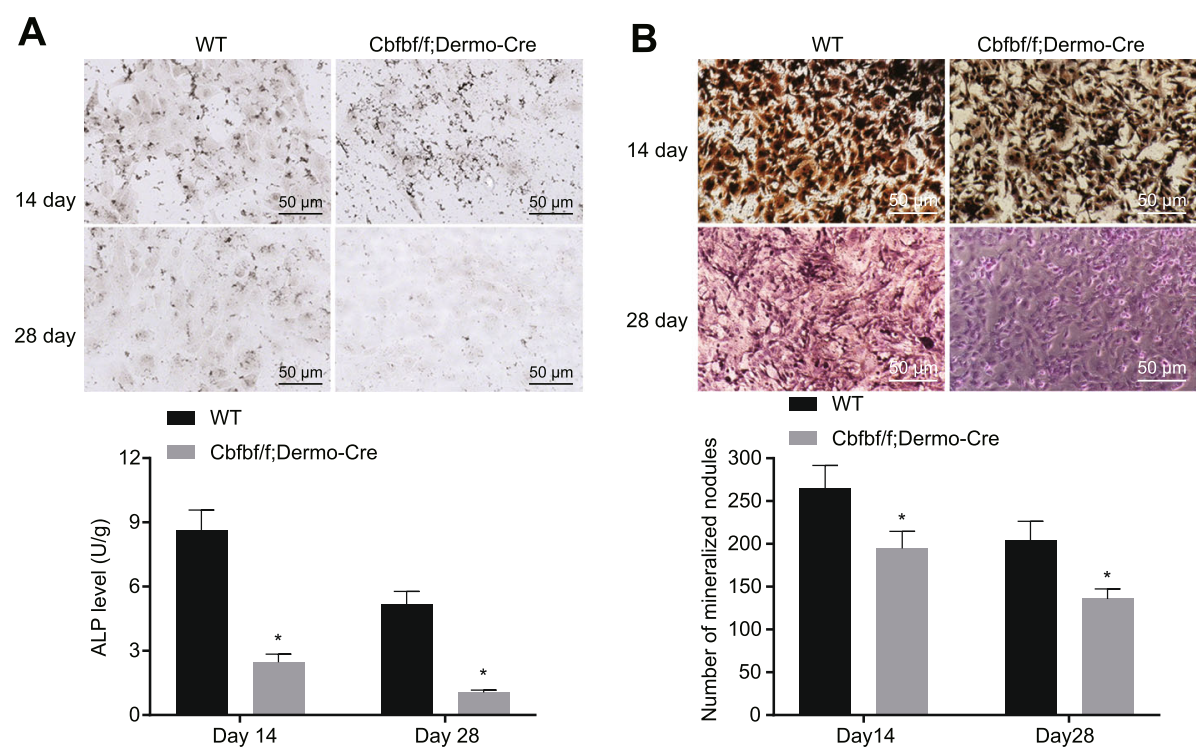

Fig. 4 Cbfb knockout inhibits ALP activity and mineralization in osteoblasts. a ALP staining $(\times 200)$ analysis of ALP activity; b von Kossa staining ( $\times 200)$ analysis of mineralization of osteoblasts. Measurement data were expressed as mean \pm standard deviation. Data comparison was conducted using independent samples $t$ test. ${ }^{*} p<0.05$ versus the WT group. $n=3$ 

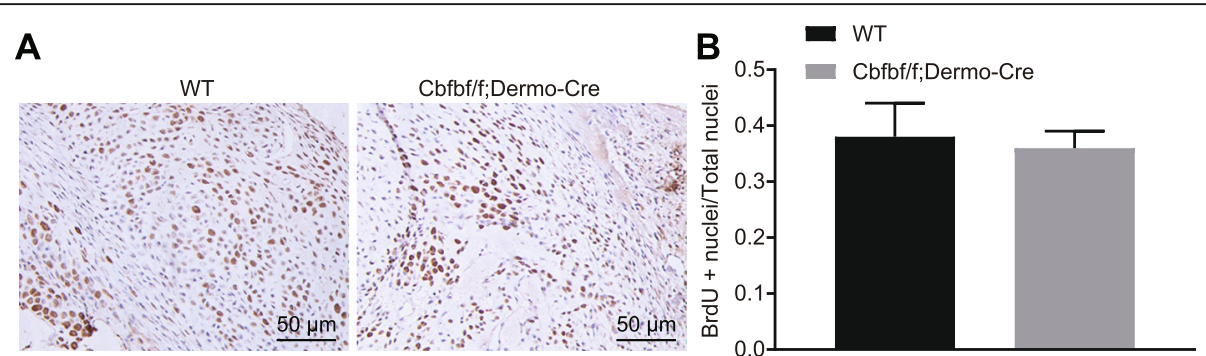

Fig. $5 \mathrm{Cbfb}$ knockout exhibits few effects on osteoblast proliferation. a BrdU assay ( $\times 200$ ) for osteoblast proliferation. $\mathbf{b}$ The proportion of BrdUpositive cells at panel a

[24]. Therefore, Cbfb might actively participate in the processes of skeletal development as well as fracture healing.

The Cbfb knockout mice were observed to exhibit downregulated PCNA and collagen II expression. Collagen II, which is known to regulate chondrogenesis of mesenchymal stem cells, demonstrably has the potential to facilitate osteogenesis and suppress adipogenesis during early stages of mesenchymal stem cell differentiation [25]. Stegemann et al. also revealed collagen II to be a key factor in enhancing chondrogenic differentiation in agarose-based modular microtissues [26]. PCNA is widely accepted to be involved in distinct pathways of DNA post-replication repair [20, 27]. In addition to DNA repair, PCNA also plays a key role in other fundamental cellular processes, such as chromatin remodeling, sister chromatid cohesion, and cell cycle control [28]. In the presence of $\mathrm{Cbfb}$ knockdown, the differentiation of chondrocytes and osteoblasts is observed to be severely inhibited in vitro [15]. Hence, knockout of Cbfb can result in conspicuously increased expression of PCNA and collagen II.

Additionally, our findings indicated that $\mathrm{Cbfb}$ knockout can inhibit ALP activity and mineralization of osteoblasts. Extracellular matrix mineralization represents an essential physiological process in the formation of teeth and bones, as well as in growth plate cartilage formation during skeletal growth [29]. ALP activity is known to be a serum biochemical marker of bone formation and has been verified to be a clinically useful tool in predicting fractures with a risk of nonunion and for monitoring the progress of healing [30]. Diminished ALP activity and mineralization in the MC3T3-E1 osteoblast-like cell line can result in delayed osteoblast differentiation [31]. IL-6 is an important factor in the early stages of fracture healing, and mice with IL- 6 knockout presented with delayed callus maturation, mineralization, and remodeling during fracture healing when compared to the callus of WT mice [32].

Cbfb knockout disrupted osteoblast differentiation, which was evidenced by decreased expression of ALP, Bglapl, Runx2, and SPPL as well as the inhibited protein expression of Osteocalcin, Atf4, and Osterixin in $\mathrm{Cbfb}$ knockout mice. On the other hand, BrdU results showed no effects of Cbfb knockout caused on osteoblast proliferation. However, the expression of the chondrocyte maturation markers Runx2, Osterix, and Osteopontin was significantly reduced in $\mathrm{Cbfb}$ knockout mice relative to the WT mice [33]. Another study revealed that microRNA145 physiologically regulates bone formation and osteoblast differentiation by forming a regulatory microRNA network through altered $\mathrm{Cbfb}$ expression [11]. Moreover, in addition to facilitating chondrocyte differentiation for the growth and maintenance of the skeleton in postnatal mice, $\mathrm{Cbfb}$ also promotes osteoblast differentiation [10].

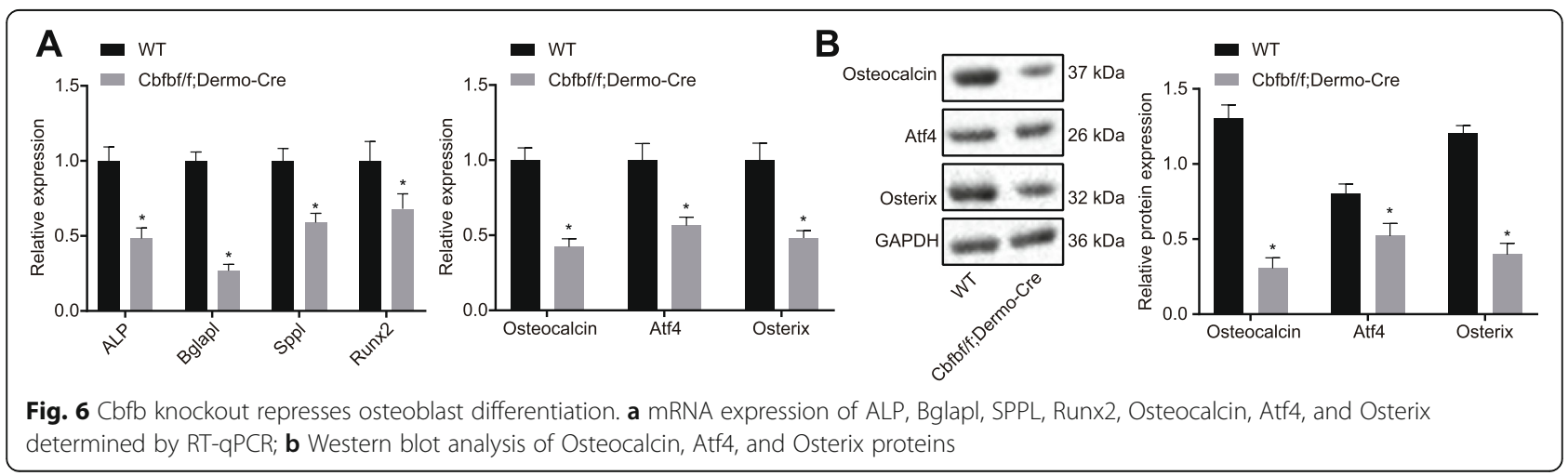




\section{Conclusion}

The key findings obtained from the present study confirm our prediction that $\mathrm{Cbfb}$ could potentially stimulate osteoblast differentiation and fibula fracture healing. Furthermore, Cbfb emerges a new biomarker and target for treatment of fibula fracture. As we are uncovering the $\mathrm{Cbfb}$-mediated mechanisms in osteoblast differentiation, new strategies and targets may emerge for therapies that prevent and treat fractures. Under the experiment conditions, Cbfb conditional knockout may be affected by various factors, such that the generalization of experimental results calls for some caution. Further studies are required to understand fully the specific molecular mechanistic actions of $\mathrm{Cbfb}$ conditional knockout, in advance of clinical translation of this therapeutic approach.

\section{Abbreviations}

Cbfb: Core-binding factor beta; PCNA: Proliferating cell nuclear antigen; ALP: Alkaline phosphatase; WT: Wild type; SP: Streptavidin-perosidase; PCNA: Proliferating cell nuclear antigen; EDTA: Ethylenediamine tetraacetic acid; PVDF: Polyvinylidene fluoride; ECL: Enhanced chemiluminescence

\section{Supplementary Information}

The online version contains supplementary material available at https://doi. org/10.1186/s13018-021-02410-9.

Additional file 1: Supplementary figure 1. Schematic view of the modeling process and the $X$-rays at each time point. $A$, the modeling process of WT mice at days 1, 14, and 28 following fracture; B, the modeling process of $\mathrm{Cbfbf} /$; Dermo-Cre mice at days 1, 14, and 28 following fracture.

Additional file 2: Supplementary Table 1. Primer sequences for reverse transcription quantitative polymerase chain reaction.

\section{Acknowledgements}

We acknowledge and appreciate our colleagues for their valuable efforts and comments on this paper.

\section{Authors' contributions}

Conceived and designed the experiments: TMG, YLX. Performed experimental: TMG, YLX, ZNC, XHW. Performed experimental validation: ZNC, $X H W$. Analyzed the data and conceived figures and tables: HYZ, LY, YY. Contributed to the reagents/materials: HYZ, LY, YY. Wrote the paper: TMG, YLX. Contributed to the writing of the manuscript: HYZ, LY, YY. The authors revised and approved the final version of the manuscript.

\section{Funding}

This study was supported by the Xianyang Young and Middle-aged Science and Technology Innovation Leading Talents Project in 2018 [Xiankefa (2018) 64], Shaanxi Administration of Traditional Chinese Medicine Project in 2019 (2019-GJ-LC003), the Project of the Department of Science And Technology in Shaanxi Province (2020JM-702), and Key Innovation Project of Xianyang Central Hospital in 2019 (2019Z-02).

\section{Availability of data and materials}

The datasets generated during and/or analyzed during the current study are available from the corresponding author on reasonable request.

\section{Declarations}

\section{Ethics approval and consent to participate}

All experimental procedures were in strict accordance with the requirements of the Animal Ethics Committee of Xianyang Central Hospital. Extensive efforts were made to ensure minimal suffering of the animals used during the study.

\section{Consent for publication}

Not applicable.

\section{Competing interests}

The authors declare that they have no competing interests.

\section{Author details}

${ }^{1}$ The Second Department of Orthopedics, Xianyang Central Hospital, Xianyang 712000, People's Republic of China. ${ }^{2}$ The Pharmacy Department, Xianyang Central Hospital, Xianyang 712000, People's Republic of China. ${ }^{3}$ The Second Department of Orthopedics, Shaanxi Traditional Chinese Medicine Hospital, Xi'an 710003, People's Republic of China.

Received: 7 January 2021 Accepted: 6 April 2021

Published online: 14 May 2021

\section{References}

1. Ma H, Wang C, Wei Q, Li ZH, Yu BQ. Double plating for the treatment of distal tibia and fibula fractures: case series of twenty five patients. Eur Rev Med Pharmacol Sci. 2013;17(16):2250-3.

2. Mollan SP, Burdon MA, Sinclair AJ. Treating idiopathic intracranial hypertension. JAMA Neurol. 2014;71(10):1326-7. https://doi.org/10.1001/ja maneurol.2014.2360

3. Marsell R, Einhorn TA. The biology of fracture healing. Injury. 2011;42(6):5515. https://doi.org/10.1016/j.injury.2011.03.031

4. Wang $Q, X u ~ H G$, Zhang YC, Dong $L$. Elastic nails for fibular fracture in adult tibiofibular fractures. Int J Clin Exp Med. 2015;8(6):10086-90.

5. Garrison KR, Shemilt I, Donell S, et al. Bone morphogenetic protein (BMP) for fracture healing in adults. Cochrane Database Syst Rev. 2010;6:CD006950.

6. Matsuguchi T, Chiba N, Bandow K, Kakimoto K, Masuda A, Ohnishi T. JNK activity is essential for Atf4 expression and late-stage osteoblast differentiation. J Bone Miner Res. 2009;24(3):398-410. https://doi.org/10.13 59/jbmr.081107.

7. Yamaguchi A, Komori T, Suda T. Regulation of osteoblast differentiation mediated by bone morphogenetic proteins, hedgehogs, and Cbfa1. Endocr Rev. 2000;21(4):393-411. https://doi.org/10.1210/edrv.21.4.0403.

8. He LH, Liu M, He Y, Xiao E, Zhao L, Zhang T, et al. TRPV1 deletion impaired fracture healing and inhibited osteoclast and osteoblast differentiation. Sci Rep. 2017;7(1):42385. https://doi.org/10.1038/srep42385.

9. Cairoli R, Beghini A, Turrini M, Bertani G, Nadali G, Rodeghiero F, et al. Old and new prognostic factors in acute myeloid leukemia with deranged corebinding factor beta. Am J Hematol. 2013;88(7):594-600. https://doi.org/10.1 002/ajh.23461.

10. Tian F, Wu M, Deng L, Zhu G, Ma J, Gao B, et al. Core binding factor beta (Cbfbeta) controls the balance of chondrocyte proliferation and differentiation by upregulating Indian hedgehog (Ihh) expression and inhibiting parathyroid hormone-related protein receptor (PPR) expression in postnatal cartilage and bone formation. J Bone Miner Res. 2014;29(7):156474. https://doi.org/10.1002/jbmr.2275.

11. Fukuda $T$, Ochi $H$, Sunamura $S$, Haiden A, Bando W, Inose $H$, et al. MicroRNA-145 regulates osteoblastic differentiation by targeting the transcription factor Cbfb. FEBS Lett. 2015;589(21):3302-8. https://doi.org/10.1 016/j.febslet.2015.09.024

12. Youngstrom DW, Zondervan RL, Doucet NR, Acevedo PK, Sexton HE, Gardner EA, et al. CTRP3 regulates endochondral ossification and bone remodeling during fracture healing. J Orthop Res. 2020;38(5):996-1006. https://doi.org/10.1002/jor.24553.

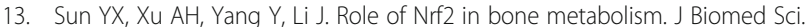
2015;22(1):101. https://doi.org/10.1186/s12929-015-0212-5.

14. Kubo Y, Wruck CJ, Fragoulis A, Drescher W, Pape HC, Lichte P, et al. Role of Nrf2 in fracture healing: clinical aspects of oxidative stress. Calcif Tissue Int. 2019;105(4):341-52. https://doi.org/10.1007/s00223-019-00576-3.

15. Qin X, Jiang Q, Matsuo $Y$, Kawane T, Komori H, Moriishi T, et al. Cbfb regulates bone development by stabilizing Runx family proteins. J Bone Miner Res. 2015:30(4):706-14. https://doi.org/10.1002/jbmr.2379.

16. Peng H, Lu SL, Bai Y, Fang X, Huang H, Zhuang XQ. MiR-133a inhibits fracture healing via targeting RUNX2/BMP2. Eur Rev Med Pharmacol Sci. 2018;22(9):2519-26. https://doi.org/10.26355/eurrev_201805_14914. 
17. Zheng Y, Liao F, Lin X, Zheng F, Fan J, Cui Q, et al. Cystathionine gammalyase-hydrogen sulfide induces runt-related transcription factor 2 sulfhydration, thereby increasing osteoblast activity to promote bone fracture healing. Antioxid Redox Signal. 2017;27(11):742-53. https://doi.org/1 0.1089/ars.2016.6826.

18. Toben D, Schroeder I, El Khassawna T, et al. Fracture healing is accelerated in the absence of the adaptive immune system. J Bone Miner Res. 2011; 26(1):113-24. https://doi.org/10.1002/jbmr.185.

19. Lee-Thacker S, Choi Y, Taniuchi I, Takarada T, Yoneda Y, Ko CM, et al. Core binding factor beta expression in ovarian granulosa cells is essential for female fertility. Endocrinology. 2018;159(5):2094-109. https://doi.org/10.121 0/en.2018-00011

20. Khan A, Hyde RK, Dutra A, Mohide P, Liu P. Core binding factor beta (CBFB) haploinsufficiency due to an interstitial deletion at 16q21q22 resulting in delayed cranial ossification, cleft palate, congenital heart anomalies, and feeding difficulties but favorable outcome. Am J Med Genet A. 2006;140(21): 2349-54. https://doi.org/10.1002/ajmg.a.31479.

21. Wu M, Li YP, Zhu G, Lu Y, Wang Y, Jules J, et al. Chondrocyte-specific knockout of $\mathrm{Cbfbeta}$ reveals the indispensable function of Cbfbeta in chondrocyte maturation, growth plate development and trabecular bone formation in mice. Int J Biol Sci. 2014;10(8):861-72. https://doi.org/10.7150/ ijbs.8521.

22. Leong PL, Morgan EF. Measurement of fracture callus material properties via nanoindentation. Acta Biomater. 2008;4(5):1569-75. https://doi.org/10.1016/ j.actbio.2008.02.030.

23. Lujan TJ, Madey SM, Fitzpatrick DC, Byrd GD, Sanderson JM, Bottlang M. A computational technique to measure fracture callus in radiographs. J Biomech. 2010;43(4):792-5. https://doi.org/10.1016/j.jbiomech.2009.10.013.

24. Kurosaka H, Islam MN, Kuremoto K, Hayano S, Nakamura M, Kawanabe N, et al. Core binding factor beta functions in the maintenance of stem cells and orchestrates continuous proliferation and differentiation in mouse incisors. Stem Cells. 2011;29(11):1792-803. https://doi.org/10.1002/stem.722.

25. Chiu LH, Yeh TS, Huang HM, Leu SJ, Yang CB, Tsai YH. Diverse effects of type II collagen on osteogenic and adipogenic differentiation of mesenchymal stem cells. J Cell Physiol. 2012;227(6):2412-20. https://doi. org/10.1002/jcp.22976.

26. Tiruvannamalai Annamalai R, Mertz DR, Daley EL, et al. Collagen type II enhances chondrogenic differentiation in agarose-based modular microtissues. Cytotherapy. 2016;18(2):263-77. https://doi.org/10.1016/j.jcyt.2 015.10.015.

27. Strzalka W, Bartnicki F, Pels K, Jakubowska A, Tsurimoto T, Tanaka K. RAD5a ubiquitin ligase is involved in ubiquitination of Arabidopsis thaliana proliferating cell nuclear antigen. J Exp Bot. 2013;64(4):859-69. https://doi. org/10.1093/jxb/ers368.

28. Chen Z, Zhang W, Yun Z, Zhang X, Gong F, Wang Y, et al. Ubiquitinlike protein FAT10 regulates DNA damage repair via modification of proliferating cell nuclear antigen. Mol Med Rep. 2018;17(6):7487-96. https://doi.org/10.3892/mmr.2018.8843.

29. Murshed M, Harmey D, Millan JL, et al. Unique coexpression in osteoblasts of broadly expressed genes accounts for the spatial restriction of ECM mineralization to bone. Genes Dev. 2005;19(9):1093-104. https://doi.org/1 $0.1101 /$ gad. 1276205

30. Komnenou A, Karayannopoulou M, Polizopoulou ZS, Constantinidis TC, Dessiris A. Correlation of serum alkaline phosphatase activity with the healing process of long bone fractures in dogs. Vet Clin Pathol. 2005;34(1): 35-8. https://doi.org/10.1111/j.1939-165X.2005.tb00006.x.

31. Zhi J, Sommerfeldt DW, Rubin CT, Hadjiargyrou M. Differential expression of neuroleukin in osseous tissues and its involvement in mineralization during osteoblast differentiation. J Bone Miner Res. 2001;16(11):1994-2004. https://doi.org/10.1359/jbmr.2001.16.11.1994.

32. Yang X, Ricciardi BF, Hernandez-Soria A, Shi Y, Pleshko Camacho N, Bostrom MPG. Callus mineralization and maturation are delayed during fracture healing in interleukin-6 knockout mice. Bone. 2007;41(6):928-36. https://doi.org/10.1016/j.bone.2007.07.022

33. Park NR, Lim KE, Han MS, Che X, Park CY, Kim JE, et al. Core binding factor beta plays a critical role during chondrocyte differentiation. J Cell Physiol. 2016;231(1):162-71. https://doi.org/10.1002/jcp.25068

\section{Publisher's Note}

Springer Nature remains neutral with regard to jurisdictional claims in published maps and institutional affiliations.

\section{Ready to submit your research? Choose BMC and benefit from:}

- fast, convenient online submission

- thorough peer review by experienced researchers in your field

- rapid publication on acceptance

- support for research data, including large and complex data types

- gold Open Access which fosters wider collaboration and increased citations

- maximum visibility for your research: over $100 \mathrm{M}$ website views per year

At BMC, research is always in progress.

Learn more biomedcentral.com/submissions 